\title{
A Rare Case of Thoracal Spine Lymphangioma
}

\author{
Ercan Bal ${ }^{1 *}$, Tuğberk Özdemir'1, Karabekir Ercan², Ayșe Dilşad Kuratmer³, Fazlı Erdoğan³, Mahmut \\ Nedim Aytekin ${ }^{4}$ and Ömer Faruk Türkoğlu ${ }^{5}$ \\ ${ }^{1}$ Department of Neurosurgery, Ankara Ylldırım Beyazıt University School of Medicine, Turkey
}

${ }^{2}$ Department of Radiology, Ankara City Hospital, Turkey

${ }^{3}$ Department of Pathology, Ankara Yıldırım Beyazıt University School of Medicine, Turkey

${ }^{4}$ Department of Orthopedics and Traumatology, Ankara Yıldırım Beyazıt University, Turkey

${ }^{5}$ Department of Neurosurgery, Ankara City Hospital, Turkey

*Corresponding author: Ercan Bal, Department of Neurosurgery, Ankara Ylldırım

Received Date: March 25, 2019

Beyazıt University School of Medicine, Ankara, Turkey.

Published Date: April 04, 2019

\begin{abstract}
Lymphangiomas are benign hamartomatous lesions made of cysts and believed to be the result of lymphatic system's abnormal development. They may be present in the spinal ekstradural space or more rarely in the intradural space. They are commonly confused with schwannoma, neurofibroma and meningioma at the stage of prediagnosis. A case of thoracic lymphangioma has been presented in the light of literature data in this case report.
\end{abstract}

Keywords: Ekstradural; Lymphangioma; Thoracal spine

Abbreviations: CT: Computed Tomography; MRI: Magnetic Resonant Imaging

\section{Introduction}

Lymphangioma is one of the rarely observed tumors of soft tissue and it develops very rarely in the spinal epidural space [1-9], and histologically classified as cavernous, capillary and cavernous lymphangioma. It may be congenital or acquired $[9,10]$. They may be present in the spinal epidural space or more rarely in the intradural space $[3,6,10]$. They are found as an isolated mass or metastasis of a primary mediastinal lesion if they are present in the epidural space [9]. They are commonly confused with schwannoma, neurofibroma and meningioma at the stage of PR diagnosis. It may be treated by surgical resection in the symptomatic lymphangiomas. Its recurrence indicates that it is a residual tumor rather than malignant transformation [8]. A case of thoracic lymphangioma has been presented in the light of literature data in this case report.

\section{Case Presentation}

The 30-year old female patient without a medical history of previous trauma or disease underwent tests performed for her complaints of severe dorsal pain that has continued for the recent six months revealed epidural lesion and the patient received physical therapy and medical management. However, she applied to our clinic because her complaints did not regress. The neurological examination of the case showed normal motor muscle strength, normal deep tendon reflex and normal proprioceptive sensation. No sensory deficit was found except hyperesthesia compliant with the level of T8-T9. No abnormality was found in the thoracic radiography and thoracic CT (Computed Tomography) imaging. However, thoracic MRI (Magnetic Resonant Imaging) encountered a lesion which occupied the right epidural space and displaced the cord to the left. The lesion was cystic, multilobulated, homogeneous and hyperintense on the T2-weighted images, homogeneous and hyperintense on the T1-weighted images, non-contrast enhancing with IV gadolinium MRI and extending to the right neural foramen (Figure 1). Surgical therapy was decided by discussing her condition with the patient since the dorsal pain of the patient was severely and no regression was achieved in the complaints by conservative treatments in the patient PR diagnosed with cystic schwannoma.

T8 laminectomy was performed in the patient revealed a cyst with a surrounding thin wall and clear interior appearance which compressed the cord at the right side of the dura mater. Without 
the cyst was evacuated, the microsurgical technique was used to dislodge the cyst wall together with the gross total excision. (Figure 2) Intraoperative neuromonitoring was used during the operation and sensory-evoked potentials, motor-evoked potentials and electromyographic changes were controlled. No perioperative and postoperative complication developed. The result of the pathological examination was evaluated as lymphangioma. The MRI examination of the patient performed at the postoperative sixth month encountered gross total resection of the lesion (Figure $1 \& 2)$

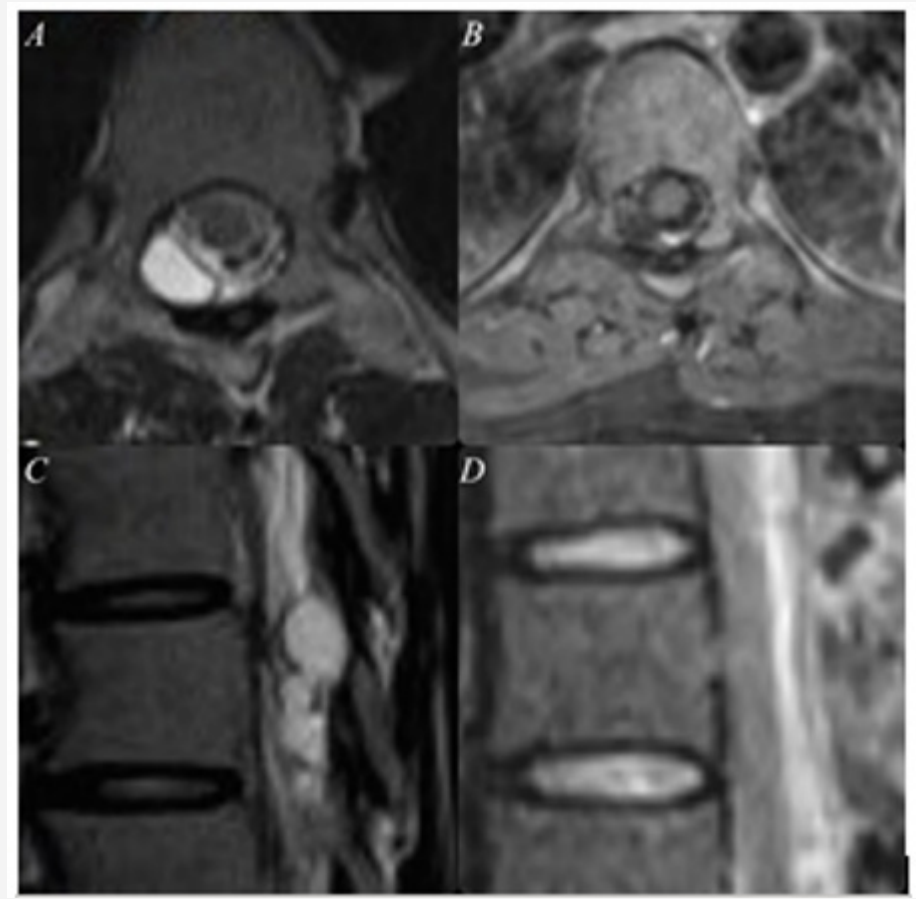

Figure 1: Thoracic MR imaging encountered a lesion which occupied the right epidural space and displaced the cord to the left. AC; The lesion was cystic, multilobulated, homogeneous and hyperintense on the T2-weighted images. B; non-contrast enhancing with IV gadolinium MR images and extending to the right neural foramen. D; postoperative examination of the patient performed at the postoperative sixth month encountered gross total resection of the lesion.
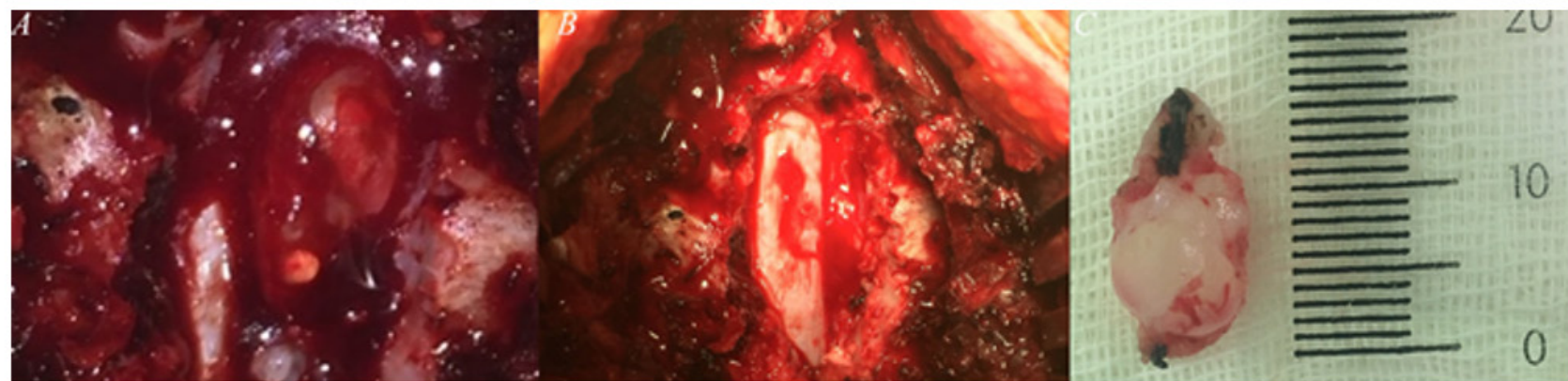

Figure 2: AT8 laminectomy was performed in the patient revealed a cyst with a surrounding thin wall and clear interior appearance which compressed the cord at the right side of the dura mater. B, C; Without the cyst was evacuated, the microsurgical technique was used to dislodge the cyst wall together with the gross total excision.

\section{Discussion}

Lymphangiomas are the benign lesions that are rarely found in the spinal canal and composed of abnormally dilated canals covered with endothelium including lymphocytes and cysts $[6,8,10]$. Even though, its pathophysiology is not completely clarified yet, it is a malformation resulting from the sequestration of the lymphatic tissue that could not establish a normal communication with the lymphatic system during fetal development according to a conclusion [10]. They are the acquired lesions that originate from the obstruction of the lymphatic system according to another conclusion [11]. They are usually slowly growing lesions that do not manifest malignant conversion. Even differential diagnosis between lymphangioma, hemangioma or hemolymph angioma may be complicated, there is no difference between them in terms of symptoms, clinical course, prognosis or treatment modalities [12]. However, it has been also concluded in the literature that lymphangiomas demonstrate less spontaneous involution than congenital hemangiomas [13].

Lymphangiomas may be confused with schwannomas, neurofibromas, meningiomas, sarcomas and metastatic carcinomas at the time of initial radiological diagnosis since they are rarely found in the spinal epidural field. There is no case series associated 
with spinal lymphangioma cases in the literature yet. Ten cases have been reported in the recent 30 years in the literature. Two of these cases were pediatric patients $[7,11]$. Mean age of the cases in the literature was 40.7 (1-83) years. The lesions were completely dissected with laminectomy in 8 of these 10 cases and no revision was needed. Revision was needed in one of the reported cases. This case was operated twice because of residual tumor and recurrence but not due to malignant transformation. A cystoperitoneal shunt was inserted during the last operation of this cases [9]. Only needle aspiration biopsy was performed in one case by the authors since lesion was located in a very long segment at the C2-T11 level in this patient, it was decided to follow-up this case with one-year intervals without resection of the lesion. No data on postoperative clinical condition of this patient was available.1 Spinal epidural hematoma was detected in one of the pediatric cases by MRI performed after ascending paresis and subsequent paraplegia in the literature. This case was recovered dramatically after the performed spinal decompression and was operated for mediastinal lymphangioma 2 months later [11].

The most common symptom in the epidural lymphangiomas are pain, numbness and progressive paraparesis. [1,3-5,8-9,14] There may be within some month's interval between pain and occurrence of the neurological symptom since they are slowly growing lesions. They are indicated with surgical treatment when they cause neural compression or neural instability [12]. Gross total dissection of the tumor provides recovery. Therefore, it should be attempted to respect the cyst together with its wall during the surgical treatment as far as possible. The reason of recurrence is the residual tumor tissue and usually the remained cyst wall rather than malignant transformation [9]. It has been reported in the literature that these caused also epidural hematoma in a pediatric case [11]. Surgical therapy was decided in our case because of resistant dorsal pain despite the conservative management and cystic schwannoma considered as PR diagnosis. No relapse or residual tumor was encountered in the follow-up examination since cyst could be resected without compromising the integrity of the cyst wall. Instrumentation and fusion were also not needed since only laminectomy was performed.

\section{Conclusion}

Spinal lymphangiomas are the rarely found tumors of the spinal canal. It can be confused another spine tumor like as schwannoma The definitive management of spinal lymphangiomas is surgical excision like the other cystic lesions of the spinal canal. Surgical management is necessary if they cause neurological compression or neural instability. The most important factor of recurrence or relapse is incomplete resection of the tumor by remaining its wall.

\section{Declarations}

Ethics approval and consent to participate Approved by University of Ankara Yıldırım Beyazıt- Atatürk Training and Research Hospital Neurosurgery department as non-human subjects research, as appropriate for case reports.
Patient consent: The patient has consented to the submission of the case report for submission to the journal.

Data available statement: The datasets generated during and/or analyzed during the current study are available from the corresponding author on reasonable request.

Authors' contributions: EB, TÖ and ÖFT participated in the sequence alignment and drafted the manuscript. EB, TÖ, ADK, MNA participated in the design of the study. EB and TÖ did the operation work. EB, TÖ, KE, ADK, and FE collected the data and carried out the follow up. EB searched the relevant literature. EB. TÖ and MNA conceived of the study and participated in the design and coordination and helped to draft the manuscript. All authors read and approved the final manuscript.

\section{Acknowledgment}

None.

\section{Conflict of Interest}

No conflict of interest.

\section{References}

1. Ha BY, Park JB, Kim YM, Lyo IU (2010) Lymphangioma in the epidural space of the thoracic spine. J Korean Neurosurg Soc 47: 403-405.

2. Saito T, Terada K, Tsuchiya K, Oda Y, Tsuneyoshi M, et al. (1999) Lymphangioma presenting as a dumbbell tumor in the epidural space of the lumbar spine. Spine (Phila Pa 1976) 24: 74-76.

3. Kanamori M (2004) Cystic lymphangiomas of the cauda equina. Spine J 4:357-359

4. Jiang YG, Xiang J, Zhang L (2006) Intraspinal lymphangioma: 2 case reports and literature review. Surg Neurol 66: 430-436.

5. Chu M, Li G, Wei L, Lin Y, Qi J, et al. (2007) A rare case of cavernous lymphangioma in the epidural space of the cervicothoracic spine. Spine (Phila Pa 1976) 32: E48-51.

6. Mc Loughlin GS, Nocturn JG, Dauser RC, Sciubba DM, Gokaslan ZL, et al. (2008) Mediastinal lymphangioma presenting as an acute epidural hematoma. J Neurosurg Pediatr 1: 474-476.

7. Lee SC, Moon SG, Kim NR, Choe WJ, Moon WJ (2011) Cervical epidural lymphangioma presenting as a hemorrhagic cyst: a case report. Spine (Phila Pa 1976) 36: E1117-1120.

8. Kerolus MG, Patil J, Kurian A, Sani S (2016) Intradural cavernous lymphangioma of the thoracic spine: case report, technical considerations, and review of the literature. Spine J 16: e561-565.

9. Aslan K, Bekci T, Gunbey HP, Incesu L, Turgut E (2015) A rare cause of backache: epidural lymphangioma of the cervicothoracic spine. Spine J 15(8): 1900.

10. Chervenak FA, Isaacson G, Blakemore KJ, Brag WR, Hobbins JC, et al. (1983) Fetal cystic hygroma. Cause and natural history. N Engl J Med 309(14): 822-825.

11. Flanagan BP, Helwig EB (1977) Cutaneous lymphangioma. Arch Dermatol 113: 24-30.

12. Watkins RGt, Reynolds RA, Mc Comb JG, Tolo VT (2003) Lymphangiomatosis of the spine: two cases requiring surgical intervention. Spine (Phila Pa 1976) 28(3): E45-50.

13. Faul JL, Berry GJ, Colby TV, Ruoss SJ, Walter MB, et al. (2000) Thoracic lymphangiomas, lymphangiectasis, lymphangiomatosis, and lymphatic dysplasia syndrome. Am J Respir Crit Care Med 161(3): 1037-1046.

14. Pan X, Dong Y, Yuan T, Yan Y, Tong D (2017) Two cases of hemolymph angioma in the thoracic spinal canal and spinal epidural space on MRI: The first report in the literature. Medicine (Baltimore) 96: e9524. 